\title{
Cómo corrige el docente de
}

\section{Lengua Castellana}

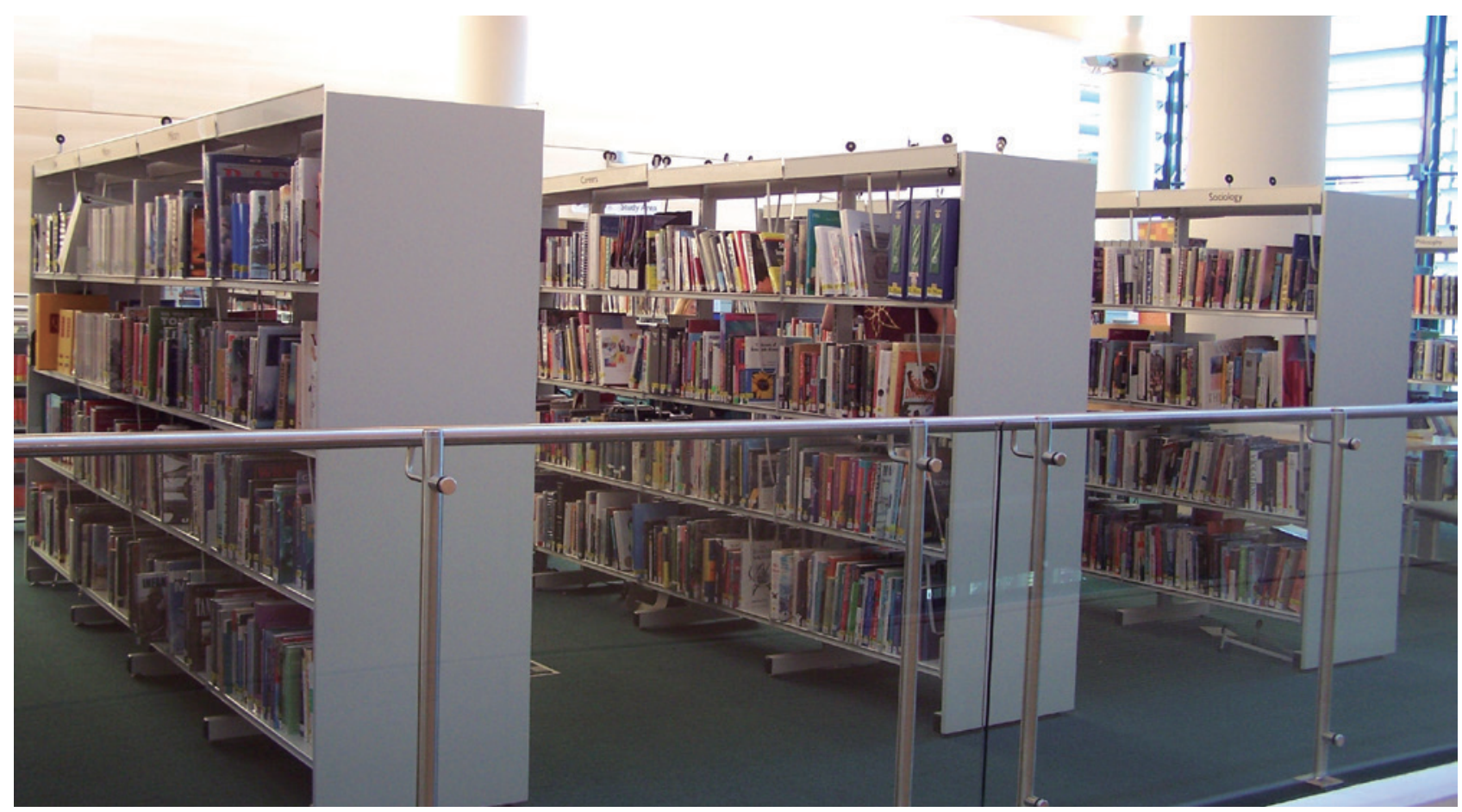

Corregir es una de las tareas más cotidianas para

un docente, pero la corrección de textos es una

actividad compleja, así que nos preguntamos:

¿cómo corrige el docente de Lengua los textos de

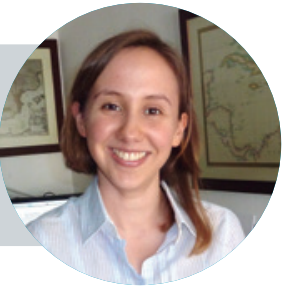

Universidad de Oviedo parralesaida@uniovi.es

sus alumnos? ¿Cómo intenta subsanar los errores

que cometen? Para contestar a estas preguntas

encuestamos a los docentes de Lengua Castellana y

Literatura de la ESO y de tercer ciclo de Educación

Primaria del municipio de Oviedo. 


\section{Ilustración 1. Preguntas a los docentes}

\section{Introducción}

La función esencial de la ortografía es garantizar y facilitar la comunicación escrita entre los usuarios de una lengua mediante el establecimiento de un código común para su representación gráfca (RAE, 2010). Asimismo, la ortografía ha sido siempre una disciplina compleja de enseñar y aprender debido a su arbitrariedad.

En la escuela se debe mostrar al alumno la necesidad de conseguir el dominio del código gráfico, descubriéndole su función, para ello el aprendizaje de la ortografía debe enmarcarse en el aprendizaje de la lengua escrita, no obstante hay que señalar que enseñar a escribir no es enseñar ortografía, aunque la norma ortográfica es imprescindible para comunicarse por escrito (CAMPS, MILIAN, BIgAS, CAMPS, \& CABRÉ, 2004).

Cuando empezamos a investigar cómo enseñaban la ortografía y la expresión escrita los docentes de Lengua Castellana, nos preguntamos cómo corregían los textos que elaboraban sus alumnos ien qué se fijaban más los docentes? ¿Se fijaban solo en la ortografía (grafías, puntuación y acentuación) o también señalaban la coherencia del texto? ¿Cómo intentaban solventar los errores de sus alumnos? ¿Les mandaban copiar la palabra errada? ¿Les proponían escribir oraciones con el término fallado para contextualizarlo? ¿Les pedían que incluyeran el vocablo en un diccionario personal?

Realizamos un amplio estudio orientado a recabar las percepciones acerca de la enseñanza y aprendizaje de la ortografía y la expresión escrita entre los docentes de lengua, con la confianza de que esta información pueda contribuir al análisis de los métodos de enseñanza de esta asignatura y, por consiguiente, realizar propuestas de mejora en la enseñanza y aprendizaje de la Lengua Castellana.

Los docentes participantes en este estudio imparten la asignatura de Lengua Castellana en tercer ciclo de Educación Primaria y en Educación Secundaria Obligatoria en el municipio de Oviedo.
Se preguntó a los docentes por la frecuencia con la que realizan las siguientes actividades:

$\checkmark \quad$ En una redacción con muchos errores de ortografía, optaría por marcarlos todos.

$\searrow \quad$ Cuando corrige los ejercicios escritos de sus alumnos, se centra principalmente en la coherencia y la cohesión del texto.

$\checkmark$ Cuando corrige los ejercicios escritos de sus alumnos, se centra principalmente en la ortografía (grafías, acentuación y puntuación).

$\searrow \quad$ Cuando corrige los ejercicios escritos de sus alumnos, se centra principalmente en el contenido del texto.

\ Cuando sus alumnos cometen un error, deben copiar varias veces la palabra correctamente.

$\checkmark \quad$ Cuando sus alumnos cometen un error, deben escribir la palabra en una oración para contextualizarla.

У Cuando sus alumnos cometen un error, deben incluir la palabra en un diccionario personal/ficha para consultar en caso de duda.

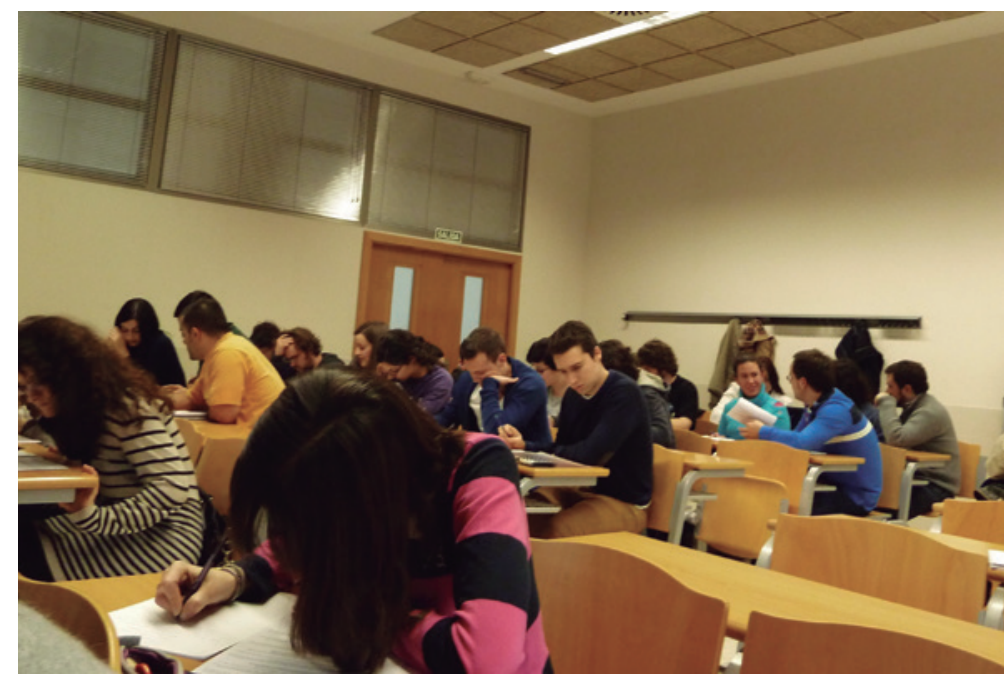

Para recabar la información elaboramos un cuestionario ad hoc y lo repartimos personalmente en todos los centros educativos de Oviedo. Tuvimos un índice de respuesta realmente alto, ya que participaron 42 centros, el $84 \%$ de los centros educativos del municipio de Oviedo y respondieron a nuestro cuestionario 198 docentes, que suponen el $74,44 \%$ de los educadores.

\section{Resultados globales}

En la tabla 1 se puede observar que los docentes que participaron en nuestro estudio son mayoritariamente mujeres, casi el $65 \%$ de la muestra; asimismo, vemos que 
Tabla 1. Perfil de los docentes participantes

\begin{tabular}{|l|l|c|c|}
\hline \multirow{2}{*}{ Sexo } & Mujeres & N & $\%$ \\
\hline \multirow{2}{*}{ Ciclo } & Hombres & 128 & $64.60 \%$ \\
\hline \multirow{2}{*}{ Tipo } & ESO & 68 & $34.30 \%$ \\
\hline & E. Primaria & 94 & $47.50 \%$ \\
\hline \multirow{2}{*}{ Edad } & Centro concertado & 104 & $52.50 \%$ \\
\hline & Centro público & 94 & $47.50 \%$ \\
\hline \multirow{2}{*}{ Localización } & Hasta 35 años & 104 & $52.50 \%$ \\
\hline & $36-45$ & 24 & $12.10 \%$ \\
\hline & $46-55$ & 38 & $19.20 \%$ \\
\hline & 56 años o más & 72 & $36.40 \%$ \\
\hline & Centro rural & 58 & $29.30 \%$ \\
\hline & Centro urbano & 11 & $5.55 \%$ \\
\hline
\end{tabular}

\section{Ilustración 2. Datos globales}

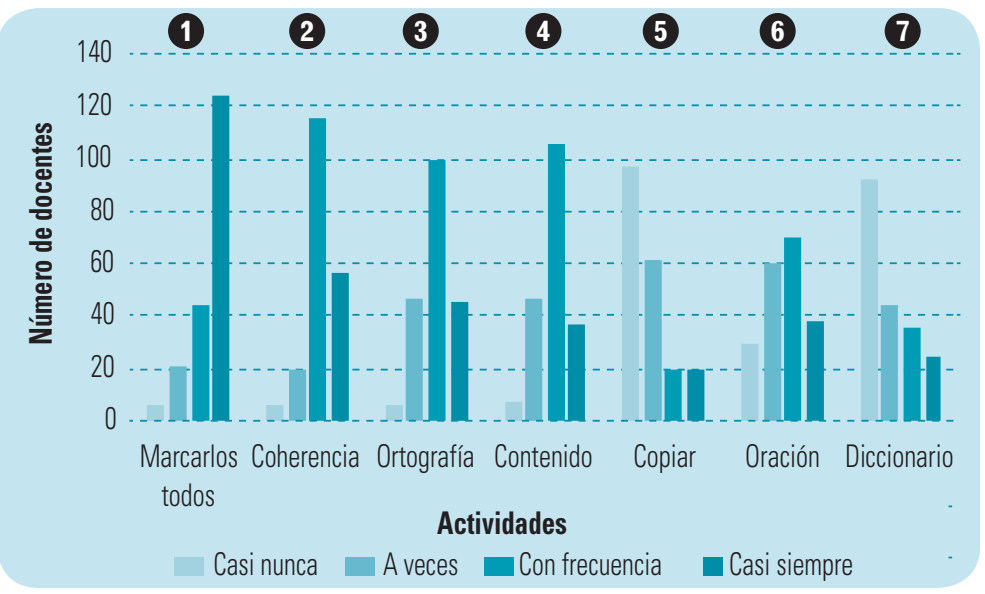

hay un equilibrio en el número de docentes de Educación Primaria y de Educación Secundaria Obligatoria, así como docentes de centros concertados y centros públicos. También puede observarse que la muestra presenta una edad alta, ya que más del $65 \%$ de la muestra tiene más de 46 años, y casi un tercio de los docentes tiene más de 56 años. Por último, queremos destacar que los docentes participantes trabajan principalmente en centros situados en el casco urbano de Oviedo.

\section{Pregunta 1}

En la ilustración 2 de datos globales, se observa que la gran mayoría de los do- centes, casi el $86 \%$, opta por marcar con frecuencia o casi siempre todos los errores que detecta en los textos de sus alumnos.

Sin embargo, autores como Anna Camps o Daniel Cassany no recomiendan marcar todos los errores de una redacción porque se satura de información al alumno y se le frustra, ya "que muchas veces el alumno no puede asimilar a la vez un número muy elevado de correcciones" (CASSANY, 1993, p. 42). Es mejor indicar aquellos errores que puedan ser comprendidos y asegurarse su solución.

\section{Preguntas 2, 3 y 4}

Si comprobamos en qué se fijan más los docentes de Lengua cuando corrigen, vemos que el $87 \%$, con frecuencia o casi siempre, se centra en la coherencia y la cohesión del texto, que el $73 \%$ atiende principalmente a la ortografía y el $72 \%$ repara sobre todo en el contenido del texto. Por tanto, se puede deducir a partir de estos datos que los docentes corrigen globalmente los textos, aunque sobre todo se centran en que estos sean coherentes y estén bien cohesionados, es decir, que los alumnos empleen marcadores textuales, expresen las ideas de forma clara y ordenada, la estructura del texto sea correcta, etc.

El proceso de corrección que siguen los docentes participantes en este estudio está avalado por expertos, como Zamel, Sommers y Cassany que recomiendan centrarse en aspectos globales como son el contenido, la coherencia, un registro adecuado, etc. No obstante, estos expertos alertan de lo inadecuado de concentrarse en aspectos más superficiales del texto, como la puntuación o una frase sin sentido.

\section{Preguntas 5, 6 y 7}

Cuando preguntamos a los docentes cómo trabajaban los errores de sus alumnos, constatamos que solo un $20 \%$ de los docentes pide a los alumnos, con frecuencia o casi siempre, que copien varias veces la grafía correcta de una palabra cuando cometen un error; mientras que el $55 \%$ de los docentes propone a sus alumnos, con frecuencia o casi siempre, que escriban la 
palabra errada en una oración, para contextualizarla.

En el caso de incluir la palabra en un diccionario personal o ficha de consulta, para revisarla en caso de duda, apreciamos que solamente el $28 \%$ de los docentes propone este método con frecuencia o casi siempre.

En relación con las actividades sugeridas para que los alumnos subsanen sus errores, la copia es una forma importante de aprender ortografía, ya que no solo se fija la huella visual del término bien escrito, sino que se fija una huella motriz. Algunos autores, como Carratalá, proponen evitar actividades repetitivas y rutinarias para fijar visualmente un término errado: se puede escribir "primero con minúsculas, luego con mayúsculas, luego dibujarla; escribirla de modo que haya que leerla de derecha a izquierda [...]" (CARRAtalá Teruel, 1993, p. 3).

También es muy importante contextualizar el término errado en una oración, ya que ayuda al alumno a comprender su significado y a fijar su huella visual.

El diccionario o ficha personal es de gran ayuda, ya que normalmente los errores que cometen nuestros alumnos se limitan a un número determinado de vocablos, por tanto, tener un diccionario personal donde puedan consultar aquellas palabras que escriben mal con frecuencia es fundamental.

Aunque la tradición escolar considera que el docente es el único capacitado para detectar los logros y los fallos de los alumnos en su proceso de aprendizaje (OGLAN, 2003), invitar a los estudiantes a que se corrijan o corrijan a sus compañeros mejora su aprendizaje respecto a que sea solamente el docente quien marque los errores e indique las soluciones (BÉLAIR, 2000).

Cuando los alumnos corrigen sus propios textos o los de sus compañeros, son más conscientes de los errores que cometen y se responsabilizan más de su propia instrucción (CASSANY, 1993; SANMARTí, 2010). Asimismo, las actividades de corrección que implican a los alumnos son más motivadoras y fomentan la reflexión y la autonomía del estudiante (D'Aquino, 2016).

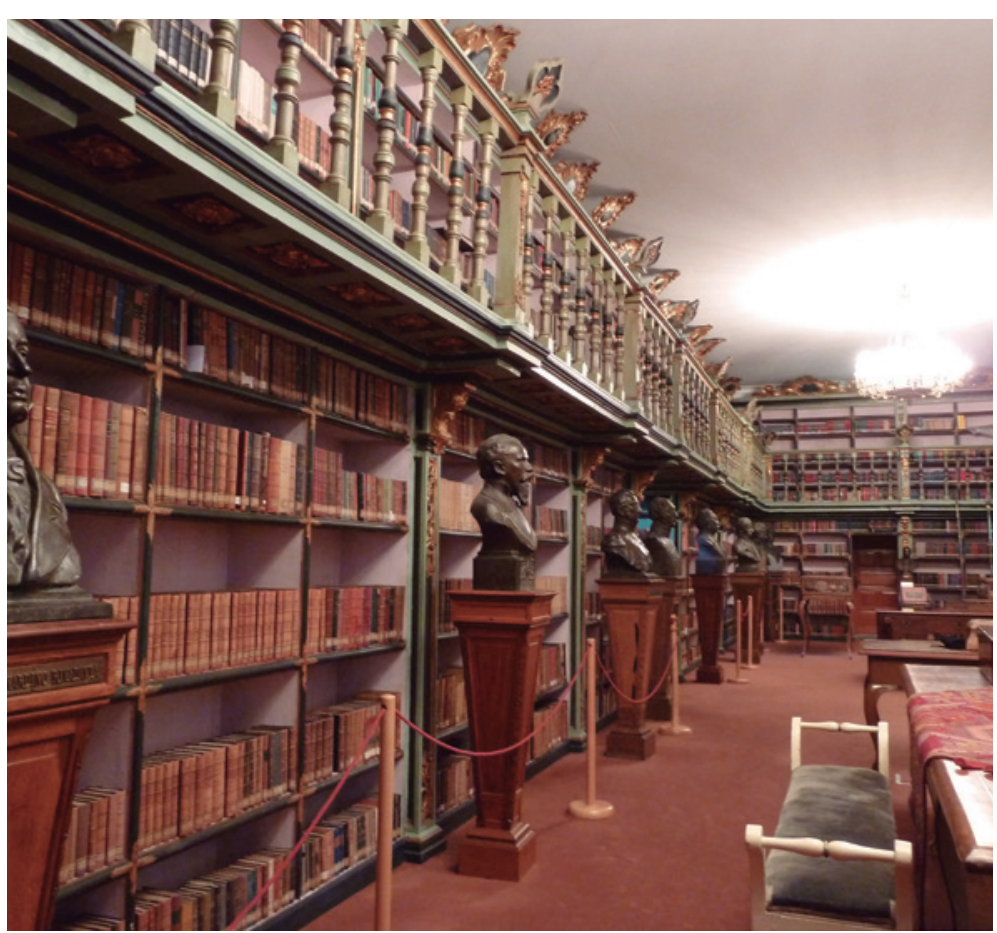

De esta manera, la corrección en parejas, aquella en la que un alumno corrige el texto de un compañero, guiada por el docente sirve para fomentar la autonomía de los alumnos.

\section{Resultados por colectivos (mujeres vs. hombres)}

Las mujeres marcan todos los errores con mayor frecuencia que los hombres: casi el 90\% de las mujeres, con frecuencia o casi siempre, marca todos los errores en una redacción que presenta muchas faltas, frente al 79\% de los hombres.

Asimismo, observamos que los hombres se centran más en la coherencia

Tabla 2. Resultados según sexo

\begin{tabular}{|l|c|c|c|c|}
\hline & \multicolumn{2}{|c|}{ Mujeres (N: 128) } & \multicolumn{2}{c|}{ Hombres (N: 68) } \\
\cline { 2 - 5 } & $\begin{array}{c}\text { Casi nunca/ } \\
\text { A veces }\end{array}$ & $\begin{array}{c}\text { Con } \\
\text { frecuencia/ } \\
\text { Casi } \\
\text { siempre }\end{array}$ & $\begin{array}{c}\text { Casi nunca/ } \\
\text { A veces }\end{array}$ & $\begin{array}{c}\text { Con } \\
\text { frecuencia/ } \\
\text { Casi } \\
\text { siempre }\end{array}$ \\
\hline 1. Marcar todos los errores & 13 & 113 & 14 & 54 \\
\hline 2. Coherencia & 18 & 109 & 6 & 62 \\
\hline 3. Ortografía & 27 & 99 & 25 & 43 \\
\hline 4. Contenido & 37 & 91 & 16 & 51 \\
\hline 5. Copiar & 106 & 22 & 51 & 16 \\
\hline 6. Contextualizar en oración & 48 & 80 & 41 & 26 \\
\hline 7. Ficha consulta & 84 & 41 & 50 & 18 \\
\hline
\end{tabular}


Proponemos dos actividades importantes dirigidas a madres y padres:

a) Revisar las libretas de sus hijos y animarlos a trabajar aquellos vocablos en los que observen errores, proponiéndoles que los copien con distintos colores y tipos de letra.

b) Proponer oraciones graciosas o rimadas para contextualizar los vocablos errados.

que las mujeres, cuando corrigen un texto: casi el $92 \%$ de los hombres se centran con frecuencia o casi siempre en la coherencia y en la cohesión del texto, frente al $85 \%$ de las mujeres. Sin embargo, son las mujeres quienes se centran más en corregir la ortografía en los textos que los hombres: casi el 78\% de las mujeres con frecuencia o casi siempre se centra en corregir la ortografía, frente al 64\% de los hombres.

Los hombres, cuando corrigen, atienden más al contenido del texto que las mujeres: casi el 77\% de los hombres, frente al $70 \%$ de las mujeres.

Las mujeres piden a sus alumnos que contextualicen la palabra que han errado en una oración con mayor frecuencia que los hombres: casi el 63\% de las mujeres realiza esta práctica con frecuencia o casi siempre, frente al 40\% de los hombres.

No hay apenas diferencias en la frecuencia con la que mujeres y hombres proponen a sus alumnos que copien las grafías correctas, ni tampoco las hay en el uso de un diccionario o ficha personal en el que sus alumnos anoten las palabras erradas.

Tabla 3. Resultados según ciclo educativo
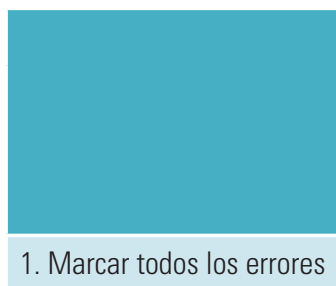

2. Coherencia

3. Ortografía

4. Contenido

5. Copiar

6. Contextualizar en oración

7. Ficha consulta

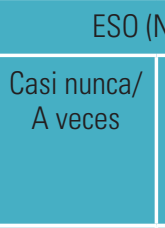

SO (N: 94 )

Con
frecuencia/
Casi
siempre

Educación Primaria (N: 104)

Casi nunca/ Con

A veces

frecuencia/

Casi siempre

\begin{tabular}{|c|c|}
\hline & \\
\hline & \\
\hline & \\
\hline & \\
\hline & \\
\hline
\end{tabular}

\begin{tabular}{|l|l|l|l|}
\hline 5 & 88 & 22 & 81 \\
\hline 17 & 77 & 8 & 95 \\
\hline 27 & 67 & 25 & 77 \\
\hline 29 & 64 & 25 & 79 \\
\hline 78 & 16 & 80 & 23 \\
\hline 42 & 51 & 47 & 57 \\
\hline 62 & 30 & 74 & 29 \\
\hline
\end{tabular}

\section{Resultados por colectivos (docentes de primaria vs. docentes de secundaria)}

Los docentes de Educación Secundaria marcan todos los errores con mayor frecuencia que los docentes de Educación Primaria: el 94\% de los docentes de ESO, con frecuencia o casi siempre, en una redacción con muchos errores, opta por marcarlos todos, frente al 78\% de los docentes de Educación Primaria.

Asimismo, el 92\% de los docentes de Educación Primaria con frecuencia o casi siempre se centran principalmente en la coherencia y en la cohesión del texto, frente al $82 \%$ de los docentes de Educación Secundaria.

Se puede observar que no hay apenas diferencias entre docentes de primaria y secundaria, con respecto a la corrección de la ortografía de los escritos.

Se observa también que el 75\% de los docentes de Educación Primaria con frecuencia o casi siempre repara principalmente en el contenido del texto, frente al $69 \%$ de los docentes de Educación Secundaria.

Comprobamos que el $23 \%$ de los docentes de Educación Primaria con frecuencia o casi siempre solicita a sus alumnos, cuando cometen un error, que copien varias veces la palabra con la grafía correcta; frente al 18\% de los docentes de Educación Secundaria Obligatoria.

Se observa que casi no hay diferencias porcentuales entre docentes de Educación Primaria y docentes de Educación Secundaria Obligatoria tanto en la propuesta de escribir oraciones para contextualizar el término errado, como en el uso de diccionarios personales o fichas de consulta.

\section{Propuestas}

A la luz de los resultados obtenidos en este estudio y teniendo en cuenta las opiniones de los expertos, sugerimos a los docentes de esta materia:

a) Emplear métodos de corrección participativos que involucren a los alumnos en las correcciones de sus propios textos o de los textos de sus compañeros, 


\section{La copia es una forma} importante de aprender ortografía, ya que no solo se fija la huella visual del término bien escrito, sino que se fija una
huella molriz

porque conseguiremos que sean más conscientes de los errores que cometen y se sentirán parte activa de su propio aprendizaje.

b) Marcar solamente aquellos errores que el alumno puede asumir, entender y llegar a solucionar sin saturarse.

c) Hacer hincapié, durante la corrección, en la estructura del texto, la claridad de las ideas y del contenido del mismo, sin olvidar los aspectos gramaticales.

d) Proponer actividades para subsanar los errores que no sean repetitivas. Como se ha observado, la copia del término correcto ayuda a fijar en la memoria tanto la huella visual como la huella motriz, pero es fundamental que esta copia se haga de manera creativa y lúdica.

e) Incluir este vocablo errado en una oración para contextualizarlo y que el alumno pueda comprender mejor su significado.

f) Por último, señalar la importancia de que los alumnos anoten en una libreta a modo de diccionario personal o ficha de consulta aquellos vocablos en los que cometen errores, para que puedan consultarlos en caso de duda •

\section{HEMOS HABLADO DE}

\section{Enseñanza obligatoria; error; corregir; profesor.}

Este artículo fue solicitado por PADRES Y MAESTROS en marzo de 2019, revisado y aceptado en junio de 2019.

\section{Ilustración 3. Balance de actividades de corrección}

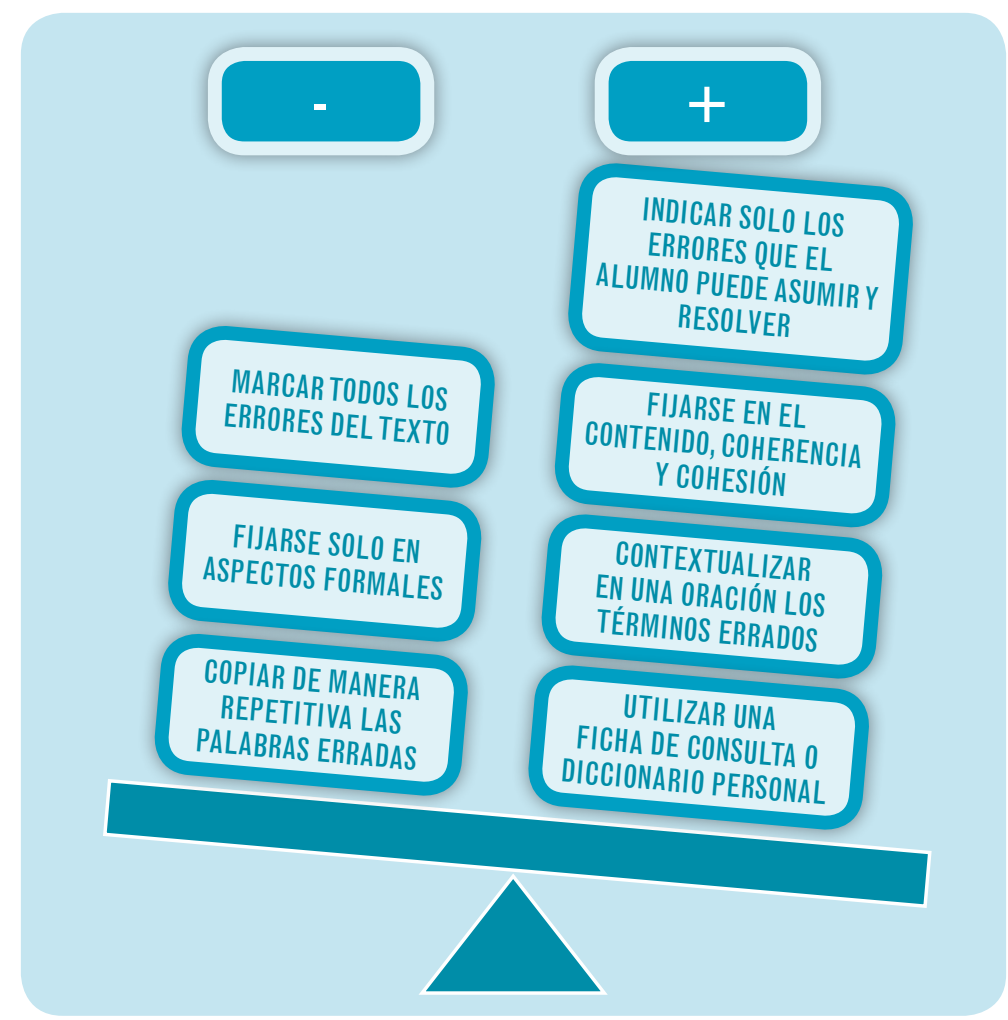

\section{(DA) DARA SABER MÁS}

BÉLAIR, L. M. (2000). La evaluación en la acción. El dossier progresivo de los alumnos. Sevilla: Díada.

Camps, A., Milian, M., Bigas, M., Camps, M., \& Cabré, P. (2004). La enseñanza de la ortografía. Barcelona: Graó.

CARBonell, L., \& MASEs, M. (1990). El proceso de enseñanza y aprendizaje. Cuadernos de Pedagogía, (185), 16-19.

Carratalá Teruel, F. (1993). La ortografía y su didáctica en la Educación Primaria. Revista interuniversitaria de formación del profesorado, (18), 93-100.

Cassany, D. (1993). Reparar la escritura. Didáctica de la corrección de lo escrito. Barcelona: Graó.

D’Aquino, A. (2016). ¡De los errores se aprende! La corrección como instrumento didáctico. Textos. Didáctica de la Lengua y de la Literatura, (71), 7-13.

Lebrero Baena, M., \& Fernández Pérez, M. (2015). La lectura: proceso de enseñanza y aprendizaje. En M. Lebrero Baena, \& M. Fernández Pérez, Lectoescritura. Fundamentos y estrategias didácticas (pp. 61-109). Madrid: Síntesis.

Oglan, G. (2003). Write, Right, Rite!. Boston: Pearson .

RAE. (2010). Ortografía de la lengua española. Madrid: Espasa.

SAnMARTí, N. (2010). 10 ideas clave. Evaluar para aprender. Barcelona: Graó.

ZayAs, F. (1996). Ortografía y apredizaje de la lengua escrita. Aula de Innovación Educativa, (56), 9-15. 